\title{
OTOT VERTEBRALIS (TRAPEZIUS, RHOMBOIDIUS, LATISSIMUS DORSI) DAN OTOT TIBIA-FIBULA (OTOT TIBIALIS, OTOT FLEXSOR LONGUS) OPERATOR SPBU KERJA POSISI BERDIRI TERBEBANI
}

\author{
Gempur Santoso \\ Dosen Fakultas Teknologi Industri Universitas PGRI Adi Buana Surabaya \\ Email: gempur_bohar@yahoo.com
}

\begin{abstract}
ABSTRAK
Operator Stasiun Pengisian Bahan Bakar Umum (SPBU) bekerja terus menerus dan lama, posisi kerja seperti itu sangat melelahkan. Populasi penelitian ini adalah operator SPBU di Kota Surabaya. Besar sampel penelitian ini adalah 50 orang operator SPBU jenis kelamin laki-laki dan perempuan. Usia responden berkisar 20 tahun sampai dengan 36 tahun. Data penelitian diambil dengan menggunakan angket/kuesioner. Analasis data dilakukan secara deskriptif kualitatif. Kesimpulan: Operator SBPU mengalami keluhan tertinggi yakni rasa sakit pada bahu kanan $(26,08 \%)$, punggung $(21,74 \%)$, betis kanan $(21,74 \%)$, dan betis kiri $(21,74 \%)$ serta tingkat kelelahan sebesar $29,09 \%$. Berdasarkan keluhan tersebut sangat besar terbebani pada otot rangka (skeletal muscle) tenaga kerja SPBU yang lebih banyak terbebani terletak pada otot trapezius, rhomboidius, dan latissimus dorsi, serta otot pada tibia dan fibula yakni otot tibialis dan otot flexsor longus. Saran: agar tenaga kerja SPBU tidak lagi bekerja posisi berdiri secara terus menerus, perlu duduk di kursi ergonomis menghadap pompa bahan bakar minyak (BBM), dan kendaraan sepeda motor yang mengisi BBM lewat terletak pada sisi kanan tenaga kerja (operator).
\end{abstract}

Kata Kunci: Kerja posisi berdiri, Keluhan, Vertebralis, Tabia, Fibula, Operator SPBU.

\section{Pendahuluan}

Bekerja dengan performen berdiri statis dalam waktu yang lama memang cepat melelahkan bagian otot tulang belekang (vertebral) daripada pada otot kaki. Seperti tenaga kerja Stasiun Pengisian Bahan Bakar Umum (SPBU) yang bekerja terus menerus berdiri selama lebih kurang 8 jam, performen kerja seperti itu sangat melelahkan.

Posisi kerja berdiri tidak ergonomis dapat menimbulkan kelelahan, nyeri, dan gangguan kesehatan lainnya. Sebagaimana Yassierli et.al. (2000) yang meneliti "tenaga kerja di industri permesinan konvensional menengah dengan fokus stasiun kerja bubut, las, press, gerinda, drill, milling dan potong manual. Pekerjaan tersebut dilakukan dengan performen berdiri. Dari 24 responden mengalami keluhan berupa kelelahan biomekanik terbanyak pada bahu kanan 20 orang dan pinggang 18 orang". Hasil penelitian Totok Budi Santoso (2004) pekerja pengrajin rotan dengan performen kerja berdiri membongkok "dari 27 orang pekerja terdapat $19(70,4 \%)$ orang pekerja mengalami nyeri punggung bawah". Sebagaimana hasil penelitian Gempur (2008) "perubahan kerja performen berdiri tegak (TG), menjadi performen berdiri setengah duduk tanpa sandaran (SDTS), dan berdiri setengah duduk pakai sandaran (SDPS) berpengaruh 
terhadap tingkat kelelahan kerja berdasar respons konsentrasi asam laktat dan glokusa secara signifikan, koefisien respons asam laktat dan glukosa dari posisi berdiri TG (laktat:4,853 mmol/kg, glukosa: $0,221 \mathrm{mg} \%$ ) pada posisi SDTS turun menjadi (laktat: $3,100 \mathrm{mmol} / \mathrm{kg}$, glukosa: $0,175 \mathrm{mg} \%$ ) dan SDPS menjadi (laktat: 3,314 mmol/kg, glukosa: 0,07089 mg\%)". Hal itu menunjukkan bahwa kerja performen berdiri TG lebih melelahkan dibanding SDTS maupun SDPS. Oleh karena itu, sebaiknya hindarkan kerja posisi berdiri tegak-statis dan ubah menjadi kerja performen berdiri setengah duduk.

Posisi kerja yang berdiri terus-menerus dan lama tidak membuat relaksasi pada otot rangka (skeletal muscle), terutama pada otot erector. Otot erector merupakan salah satu otot utama yang menahan otot tulang belakang (vertebral) agar tidak membongkok. Otot erector akan relaksasi ketika disandarkan, dan otot kaki akan relaksasi ketika duduk. Apakah operator SPBU juga mengalami keluhan, dan seberapa besar tingkat keluhan serta beberapa otot rangka yang terbebani ketika melakukan pekerjaannya?

\section{Metode Penelitian}

Populasi penelitian ini adalah operator SPBU di Kota Surabaya. Sedangkan sampelnya adalah 50 orang operator SPBU laki-laki dan perempuan tersebar di wilayah Surabaya barat, timur, selatan, utara dan tengah, masing-masih wilayah 10 orang. Cara pengambilan sampel adalah secara kriteria-random pada tenaga kerja SPBU di kota Surabaya. Usia responden berkisar 20 tahun sampai dengan 36 tahun yakni masih dalam batas usia produktif ( $<40$ tahun). Data penelitian diambil dengan menggunakan angket/kuesioner. Analasis data dilakukan secara komparasi deskriptif-kualitatif.

\section{Keluhan Otot Rangka (Skeletal Muscle) Operator SPBU}

Bedasarkan hasil data tentang tingkat keluhan tertinggi yang diderita operator SPBU lihat tabel 1, sebagai berikut:

Tabel 1. Jenis dan tingkat keluhan tertinggi pada tenaga kerja SPBU

\begin{tabular}{|l|l|l|l|}
\hline No. & \multicolumn{1}{|c|}{$\begin{array}{c}\text { Jenis Keluhan } \\
\text { Tertinggi }\end{array}$} & $\begin{array}{c}\text { Tingkat } \\
\text { Keluhan }\end{array}$ & Persentase \\
\hline 1. & Bahu kanan & Sakit & $26,08 \%$ \\
2. & Bahu kanan & Sakit sekali & $8,70 \%$ \\
3. & Punggung & Sakit & $21,74 \%$ \\
4. & Pinggang & Sakit & $13,04 \%$ \\
5. & Pinggang & Sakit sekali & $8,70 \%$ \\
6. & Lengan atas kanan & Sakit & $13,04 \%$ \\
7. & Lengan atas kiri & Sakit & $13,04 \%$ \\
8. & Betis kanan & Sakit & $21,74 \%$ \\
9. & Betis kiri & Sakit & $21,74 \%$ \\
\hline
\end{tabular}




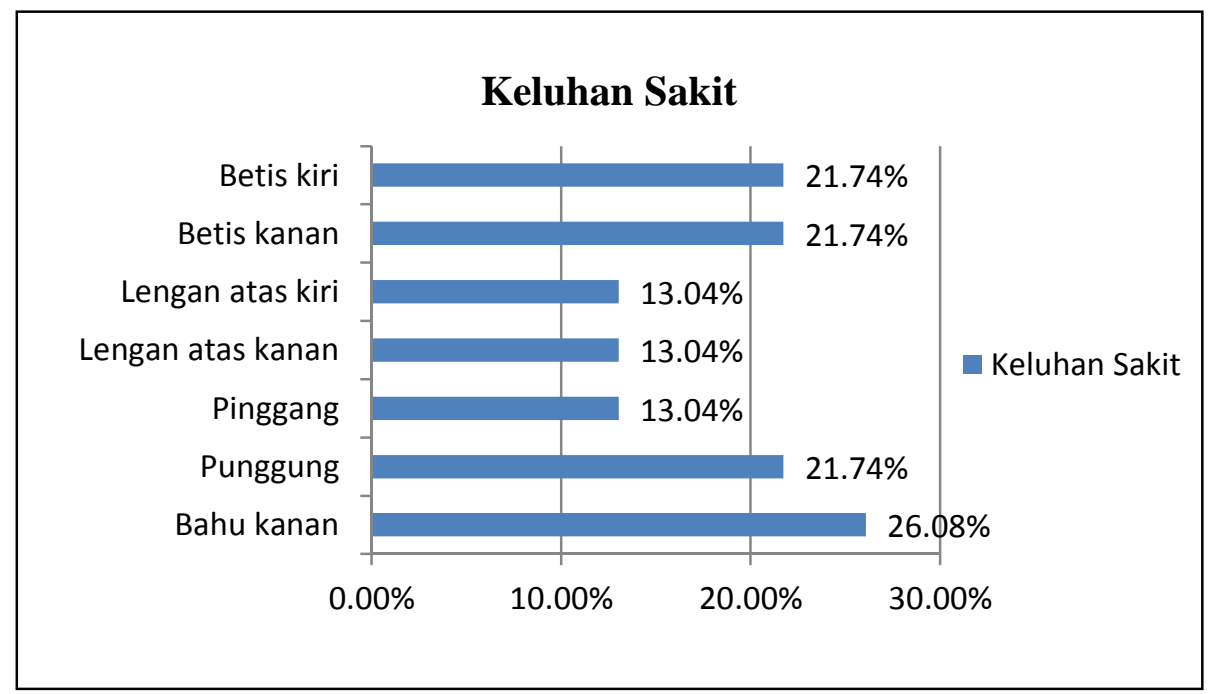

Gambar 2. Grafik Keluhan Rasa Sakit Operator SPBU

Berdasarkan data pada tabel 1 dan gambar 2 di atas bahwa tenaga operator SBPU mengalami keluhan rasa sakit tertinggi yakni pada bahu kanan $(26,08 \%)$, kemudian pada punggung $(21,74 \%)$, betis kanan $(21,74 \%)$, dan betis kiri $(21,74 \%)$. Rasa sakit pada bahu kanan, bahu kiri, dan punggung karena saat mengoperasikan kran handel bahan bakar, tangan memerlukan kekuatan menekan dan menahan. Handel kran bahan bakar digerakkan secara intermiten, atau secara tidak terus menerus, memerlukan kekuatan menahan. Pekerjaan sebagai operator SPBU saat memerlukan kekuatan tangan menahan dan menekan, maka otot biomekanik (=otot rangka yang melakukan kerja mekanik) mengalami kontraksi isokinetik. Kontraksi tersebut diteruskan kebagian otot pada bahu tulang belakang (vertebral) terutama pada punggung (thoracic dan cervical vertebral). Keluhan pada bahu, punggung dan pinggang otot tulang belakang yang banyak terlibat menurut Thomson (1981) adalah "otot trapezius, rhomboideus, dan lattisimus dorsi". Selanjutnya menurut Thomson (1981) pula bahwa "otot trapezius yang menghubungkan dasar tengkorak dan tali sendi leher, vertebral pada cervical 7 dan seluruh thoracic". Nederhand (2000) menyebutkan pula bahwa "disfungsi otot cervical dapat dilihat pada upper trapezius muscles", semua otot itu ada pada di bagian vertebral. Jadi keluhan rasa sakit pada bahu kanan - kiri dan punggung otot yang terbebani adalah otot trapezius, rhomboidius, dan latissimus dorsi (lihat gambar 3 dan 4).

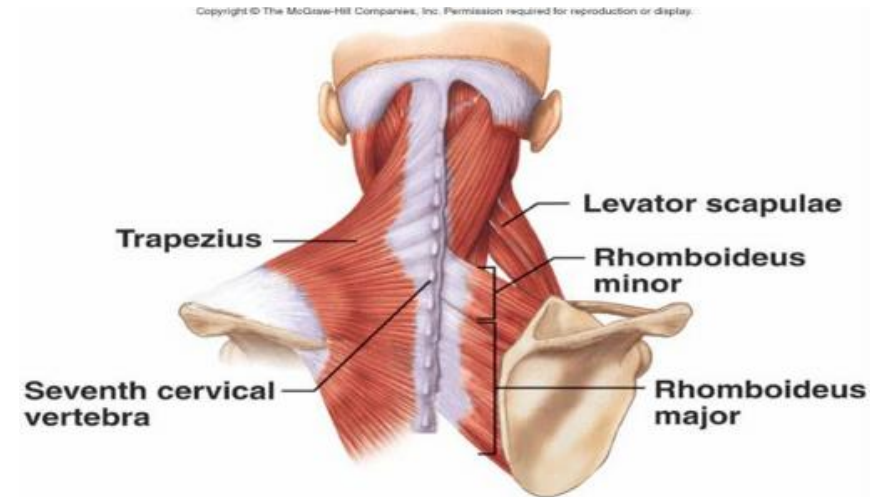

Gambar 3. Letak Otot Trapezius dan Romboideus Pada Tubuh Balakang 


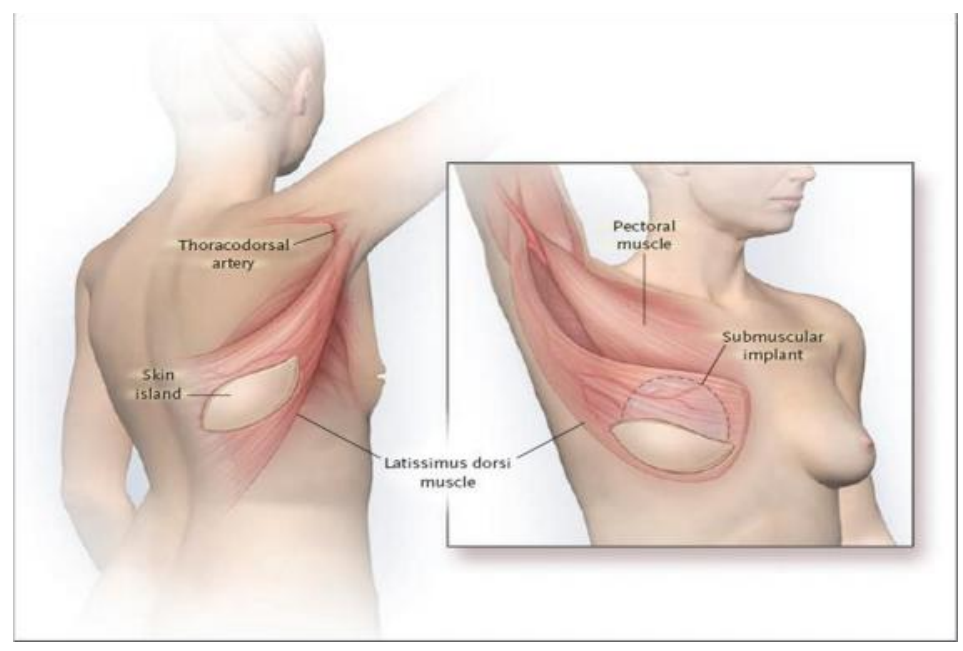

Gambar 4. Letak Otot Latissimus Dorsi

Kemudian keluhan rasa sakit pada Betis kanan dan kiri terjadi karena pada saat kerja sebagai operator SPBU memerlukan kekuatan menahan tubuh berdiri statis, otot agonis dan antagonis saling menahan tanpa ada ring of motion, maka otot biomekanik mengalami kontraksi isometrik. Guyton et.al (1997) menyebutkan bahwa "kontraksi dikatakan isometrik bila itot tidak memendek selama kontraksi”. Gerakan dan fleksi tungkai dan sendi paha menurut Ganong (1999) "otot-otot paha belakang terentang di panggul, melalui sendi panggul dan sendi lutut sampai ke tibia dan fibula, kontraksi otot belakang tersebut menghasilkan gerak tungkai sendi dan sendi paha". Jadi pada gerak statis (kontraksi isometrik) pada berdiri statis pada opreator SPBU hanya diterima betis kanan dan kiri terutama diterima oleh otot pada tibia dan fibula. Otot yang terkait tibia dan fibula menurut Ethel Slonane (2004) adalah otot tibialis posterior, tibialis anterior, dan fleksor longus "tibialis posterior terletak di sepanjang lateral tibia dibelakang tibialis anterior, dan fleksor ibu jari-jari kaki longus merupakan otot lateral di dalam sepanjang fibula bawah tendon melintang di belakang pergelangan kaki, berkelok-kelok dibalik malleoilus medial dan memanjan sampai ujung jari kaki" (lihat gambar 5a, 5b, 5c)

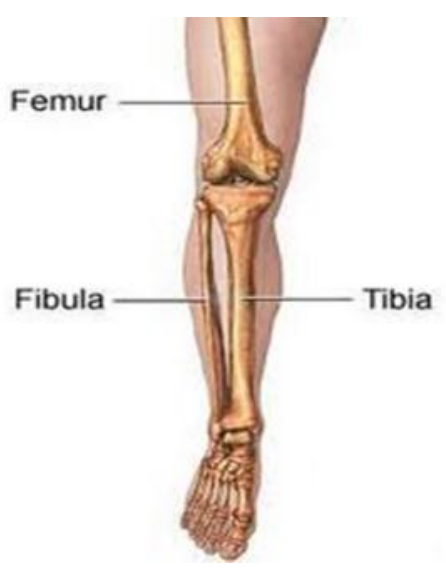

Gambar 5a. Letak Fibuli dan Tibia

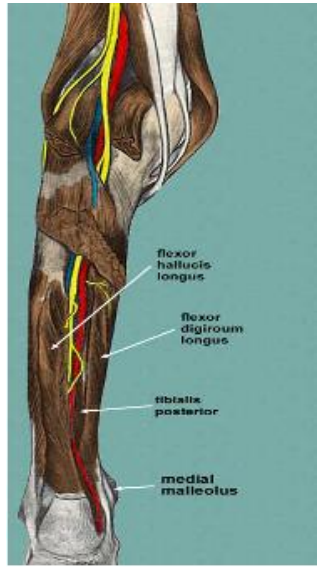

Gambar 5b. Letak Tibilais Posterior dan Flexor Longgus

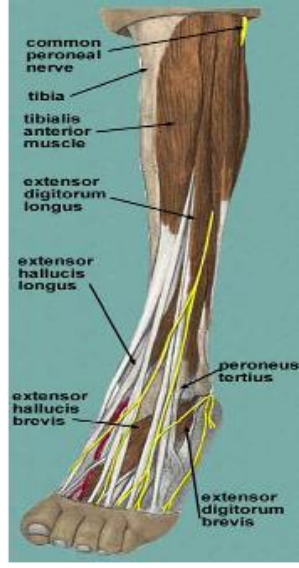

Gambar 5c. Letak Tibilais Anterior dan Extensor Longgus 
13) Otot Vertebralis (Trapezius, Rhomboidius, Latissimus Dorsi) Dan Otot TibiaFibula (Otot Tibialis, Otot Flexsor Longus) Operator SPBU Kerja Posisi Berdiri Terbebani

\section{Kesimpulan Dan Saran}

\section{A. Kesimpulan}

1. Tenaga kerja SBPU mengalami keluhan tertinggi yakni rasa sakit pada bahu kanan (26,08\%), punggung $(21,74 \%)$, betis kanan $(21,74 \%)$, dan betis kiri $(21,74 \%)$ serta tingkat kelelahan sebesar 29,09\%. Berdasarkan keluhan tersebut sangat besar pada otot rangka (skeletal muscle) tenaga kerja SPBU yang lebih banyak terbebani terletak pada otot trapezius, rhomboidius, dan latissimus dorsi, serta otot pada tibia dan fibula yakni otot tibialis dan otot flexsor longus.

\section{B. Saran}

1. Agar tenaga kerja SPBU tidak lagi bekerja posisi berdiri secara terus menerus perlu diberikan kursi ergonomis.

2. Tenaga kerja SPBU untuk posisi kerja berdiri setengah duduk sebaiknya menggunakan kursi ergonomis diletakan pada pada sisi samping pompa $\mathrm{BBM}$, jadi pompa BBM di depan operator (tenaga kerja) dan kendaraan sepeda motor yang mengisi BBM terletak pada sisi kanan operator.

\section{Daftar Pustaka}

Anna Poedjiadi, Dasar-dasar biokimia, UI-Press, Jakarta, 1994:274-275.

Becker M. Wayne, Jane B. Reece and Martin F. Poenie, The world of the cell, Third edition, The Benjamin/comings publishing company, 1999: 296325.

Ethel Slonane, Anatomi dan Fisiologi Pemula, Catakan I, EGC, 2004:150

Ganong F, William, Fisiologi Kedokteran, EGC, Edisi 17, !977

Gempur Santoso, Deteksi Kelelahan pada kerja bubut posisi berdiri terhadap fluktuasi asam laktat dan glukosa, Wahana volume 51 no. , Juni 2008: 19-26.

Guyton C. Arthur \& Hall E. John, Fisiologi kedokteran (textbook of medical physiology), EGC, 1997: 91-105.

Nederhand J. Marc, Cervical muscle dysfunction in the chronic whiplash associated grade II (WAP II), Spine Vol. 25, 2000: 1938-1943.

Peter A. Mayes, Glikolisis dan oksidasi piruvat, Biokimia Harper, Edisi 24, EGC, Jakarta, 1999: 181-189.

Totok Budi Santoso, Pengaruh posisi kerja terhadap timbulnya nyeri punggung bawah pada pengrajin rotan di desa Trangsan kabupaten Sukoharjo, Infoke Vol 8 no 1 - Maret - September 2004.

Thompson W, Clem, Manual of structural kinesiology, The CV. Mosby company, Ninth edition, London, 1981: 3-25, 111, dan 122-123.

Yassierli, Iftikar Z. Sutalaksana, Evaluasi dan analisis postur kerja dalam sistem kerja permeinan konvensional Indonesia, Proceeding Seminar Nasional Ergonomi 2000 - (162-166). 
